\title{
Further evidence for the organisation of the four sarcoglycans proteins within the dystrophin-glycoprotein complex
}

\author{
M Vainzof ${ }^{1,2}$, ES Moreira ${ }^{2}$, G Ferraz ${ }^{3}$, MR Passos-Bueno ${ }^{2}$, SK M arie ${ }^{1}$ and M Z Zatz ${ }^{2}$ \\ ${ }^{1}$ D epartamento de Neurologia, FM USP, São Paulo \\ ${ }^{2} \mathrm{D}$ epartamento de Biologia, IB-USP, São Paulo \\ ${ }^{3} \mathrm{D}$ epartamento de G enética, UF PE, Recife, PE, Brazil
}

\begin{abstract}
B ased on the pattern of distribution of the SG proteins in patients with LGM $2 C$ and 2D, and on the observed decreased abundance of dystrophin through W B in some sarcoglycans (SG) patients, we have recently suggested that $\alpha, \beta$ and $\delta$ subunits of sarcoglycan complex might be more closely associated and that $\gamma$-SG might interact more directly with dystrophin. Two additional SG patients here reported give further support to these suggestions: an L G M D 2F patient showed patchy labelling for $\gamma$-SG, despite the lack of staining of the other three SG proteins; an LGMD2C boy showed deficiency in dystrophin by means of WB and IF, comparable with an DMD manifesting carrier. These two patients represent further evidence of a closer relation of $\alpha, \beta$ and $\delta$-SG than of $\gamma$-SG and of the possible association of $\gamma$-SG with dystrophin. In addition the LGMD2C patient illustrates the potential risk of misdiagnosis using only dystrophin analysis, in cases with no positive family history, or when D NA analysis is not informative.
\end{abstract}

Keywords: sarcoglycans; muscular dystrophy; limb-girdle M D

\section{Introduction}

The dystrophin-glycoprotein complex (DGC), composed by the dystroglycan and the sarcoglycan subcomplexes, forms an important bridge across the muscle membrane, between dystrophin, in the inner cytoskeleton and merosin, in the basal lamina. ${ }^{1,2}$ The D GC may stabilise the sarcolemma and protect muscle fibres from long-term contraction-induced damage and necrosis.

Correspondence: Dr Mariz Vainzof, Depto. de Biologia IB -U SP, R . do M atão, 277, São Paulo, SP - CE P 05508-900, Brazil. Tel: 55113061 4036; Fax: 5511818 7419; E-mail: mvainzof@usp.br

R eceived 24 February 1998; revised 8 J uly 1998; accepted 18 A ugust 1998
A primary deficiency of dystrophin in Duchenne muscular dystrophy (DMD) leads to a secondary deficiency of members of the $D G C$, implying that dystrophin is necessary for the maintenance of the complex. ${ }^{3,4} \mathrm{~A}$ mong the seven mapped autosomal recessive limb-girdle muscular dystrophies, the sarcoglycanopathies (SG pathies) or L G M D 2D , 2E, 2C and 2F are caused by a primary lack of one of the sarcoglycan glycoproteins ( $\alpha$-SG, $\beta$-SG, $\gamma$-SG or $\delta$-SG ), resulting in the deficiency of the whole complex..$^{5-11}$

In a recent study we observed that the primary complete lack of $\alpha$-SG staining in LGMD2D patients may be associated with a complete lack of $\beta$ and $\delta$-SG but not of $\gamma$-SG staining. In addition, the primary lack of staining for $\gamma$-SG was associated with only a partial deficiency of $\alpha, \beta$ and $\delta$-SG proteins in some L G M D 2C 
patients. Furthermore, a secondary reduction in dystrophin amount was seen in patients with primary sarcoglycan mutations, which was most marked in patients with primary $\gamma$-SG deficiency. Based on the above findings, we have suggested that $\alpha, \beta$ and $\delta$ subunits of sarcoglycan might be more closely associated, whilst $\gamma$-SG might interact more directly with dystrophin. ${ }^{12}$

$\mathrm{H}$ ere we report two additional SG pathy patients with a 'DMD-like presentation' which gives further support to our previous study. In addition, one of them illustrates the potential risk of misdiagnosis in cases with a patchy pattern of dystrophin by means of IF methodology.

\section{Patients and Methods}

Patient 1 is a 15 -year-old girl, from a Caucasian consanguineous kindred who has three normal sibs. She was wheelchair bound at age 12 and currently shows severe weakness and is unable to raise her arms. DNA analysis showed a novel homozygous missense mutation (E262K) in exon 8 of the $\delta$-SG gene. ${ }^{13}$

Patient 2 is a 9-year-old boy, who has difficulty in running and cannot climb stairs unassisted. $\mathrm{He}$ belongs to a highly consanguineous family with 19 additional affected individuals: ten males and nine females. DNA analysis confirmed that he has the 521-T mutation in the $\gamma$-SG gene.

Dystrophin was analysed by immunofluorescence (IF) and western blot (WB) with the rabbit polyclonal $\mathrm{N}$-terminal 303-8 (kindly provided by J Chamberlain) and C-terminal monoclonal $\mathrm{Dy} 8 / 6 \mathrm{C} 5$ antibodies (kindly provided by LVB A nderson), as described elsewhere. ${ }^{14,12}$ Sarcoglycans proteins were studied by means of IF, using the following antibodies: $\alpha$-SG (A d1/20A 6, from D r LV B A nderson), $\beta-S G,{ }^{6} \gamma-S^{9}{ }^{9}$ and $\delta$-SG. ${ }^{11}$

\section{Results}

In patient 1, IF analysis of the sarcoglycan proteins revealed a total absence of $\delta-S G$, as expected, accompanied by the total absence of $\alpha-S G$ and $\beta-S G$, but only a partial deficiency of $\gamma$-SG (Figure 1 ).

In patient 2, IF analysis showed the complete absence of the four sarcoglycan glycoproteins from muscle membranes (Figure 1). However, it differed from the previous 5LGMD2C patients we had reported, who showed a positive and apparently normal pattern of dystrophin distribution on muscle fibres. In this patient, we observed a weak IF pattern of dystrophin, with some clusters of strongly positive fibres, which is comparable with the pattern we observed in some DMD manifesting carriers (Figure 1 ). In addition, a very weak dystrophin band ( +/- $10 \%$ of normal) was detected using western blot methodology, with antibody directed against the rod domain of dystrophin (Figure 2), thus confirming a dystrophin deficiency.

\section{Discussion}

In our previous report, all patients affected by L G M D 2E and 2F were severely affected; their muscles were highly degenerate and showed a total absence of the four SG glycoproteins on muscle fibres. Therefore our previous suggestion of the probable association of the SG proteins was indirectly based on observations in six LGMD2D patients who showed a primary deficiency of $\alpha-S G$ and a total deficiency of $\beta$ - and $\delta-S G$, but not $\gamma$-SG, as well as in two LGM D 2C patients, who
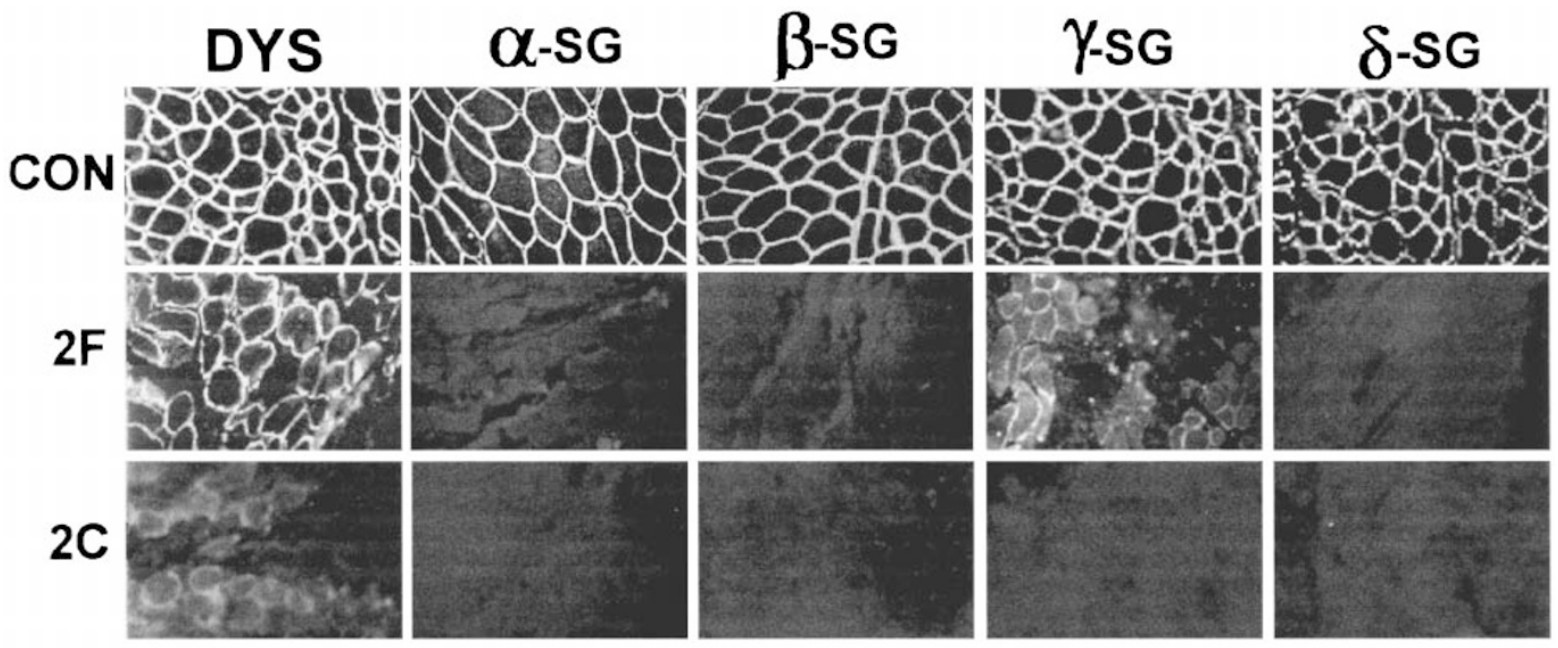

Figure 1 IF pattern of dystrophin (DYS) and the four sarcoglycans proteins in a control muscle (CON), in the patient with L G M D $2 F$ and $2 \mathrm{C}$. 


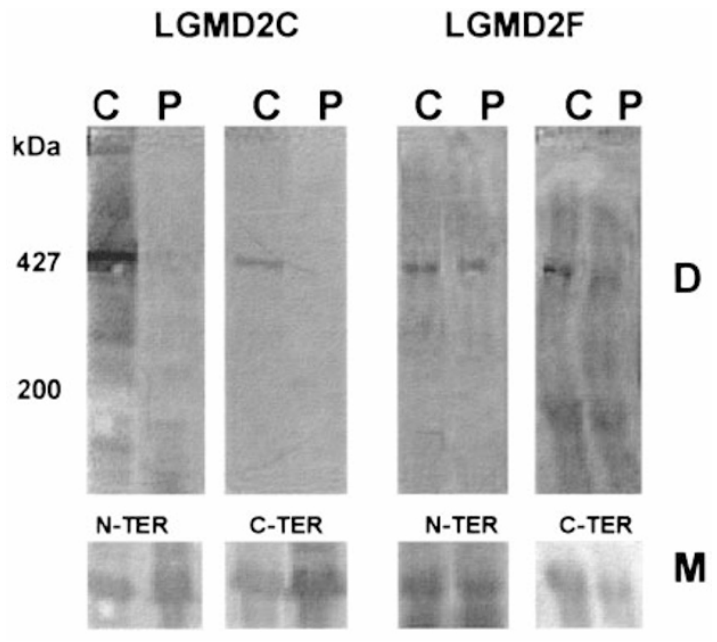

Figure 2 Dystrophin western blot, showing the dystrophin band $(D)$ in each patient $(P)$, as compared with a normal control (C), using the $\mathrm{N}$-terminal and $\mathrm{C}$-terminal antibodies for dystrophin, $\mathrm{M}=$ myosin content in muscle extract, as shown by Ponceau pre-stained blot.

had a total absence of $\gamma$-SG, but only a partial deficiency of $\alpha, \beta$ and $\delta$-SG. ${ }^{12}$

The LGMD2F patient here reported also showed patchy labelling for $\gamma$-SG, despite the absence of the other three SG proteins and therefore represents another evidence of a closer relation to $\alpha, \beta$ and $\delta$-SG than to $\gamma$-SG.

Moreover, the patchy dystrophin pattern observed in the LGMD2C ( $\gamma$-SG deficient) patient gives further support to the hypothesis of a closer association between $\gamma$-SG and dystrophin. However, since all our patients studied had the same mutation, we cannot rule out the possibility that this specific mutation affects the protein interaction within the sarcoglycan complex. In this respect it will be interesting to verify if patients with different mutations in the $\gamma$-SG gene also have the same complex disarrangement.

We have al ready shown that many SG patients had a very weak band of dystrophin using WB methodology, as a secondary effect of SG deficiency. However, this was not evident using the IF technique, which usually presents a positive pattern. ${ }^{12} \mathrm{~A}$ possible explanation is that, as reported previously for DMD heterozygotes (and mdx carriers), dystrophin present in a mosaic pattern in young individuals and manifesting carriers tends to show a more uniform arrangement on fibre sarcolemma with aging. ${ }^{15,16}$ Consequently, a deficiency in dystrophin quantity, which can occur as a patchy pattern of distribution, might be transformed to a positive pattern as dystrophin is redistributed on sarcolemma.

Finally, it is important to point out that some LGM D patients can present a reduction in the amount of dystrophin ${ }^{12}$ whilst some BMD patients can have normal dystrophin. ${ }^{17}$ Therefore, based on the low dystrophin quantity from $W B$ and the patchy pattern from IF analysis, this LGMD2C boy would have been diagnosed as having Becker muscular dystrophy, or as a manifesting DM D carrier if he had been a girl. So in the absence of a positive family history, or when DNA analysis is not informative, results concerning dystrophin must be interpreted with caution.

\section{Acknowledgements}

A ntibodies were kindly given by $D r$ Louise A nderson ( $\alpha-S G$, $\gamma$-SG and dystrophin), D r Carsten Bonnemann and Dr LM Kunkel $(\beta-S G)$, D r Elizabeth M cNally $(\gamma-S G)$, D r Vincenzo Nigro ( $\delta-S G)$ and Dr J Chamberlain (dystrophin, 303-8), to whom we are very grateful. We also wish to thank Marta Canovas for excellent technical assistance. The collaboration of the following persons is also gratefully acknowledged: $\mathrm{Dr}$ Rita CM Pavanello, Dr Ivo Pavanello Filho, Cleber Costa, A ntonia MP Cerqueira and Constância G U rbani. This work was supported by grants from Fundação de A mparo à Pesquisa do Estado de São Paulo (FAPESP), Conselho Nacional de Desenvolvimento Científico e Tecnológico $(C N P q), P R O N E X, F I N E P, P A D C T, I A E A$, and A ssociação $B$ rasileira de $D$ istrofia $M$ uscular ( $B D I M)$.

\section{References}

1 Yoshida M, O zawa E: G lycoprotein complex anchoring dystrophin to sarcolemma. J B iochem (Tokyo) 1990; 108: 748-752.

2 E rvasti J M, O hlendieck K, Kahl SD, Gaver M G, Campbell KP: Deficiency of a glycoprotein component of the dystrophin complex in dystrophic muscle. Nature 1990; 345: 315-319.

3 O hlendieck K, M atsumura K, I onasescu V V, Campbell KP: Duchenne muscular dystrophy: deficiency of dystrophin-associated proteins in the sarcolemma. Neurology 1993; 43: 1267-1268.

4 Ervasti JM, Campbell KP: A role for the dystrophinglycoprotein complex as a transmembrane linker between laminin and actin. J Cell Biol 1993; 122: 809-823.

5 Roberds SL, Leturcq F, A llamand $V$ et al: $M$ issense mutations in the adhalin gene linked to autosomal recessive muscular dystrophy. Cell 1994; 78: 625-633. 
6 Bonnemann CG, Modi R, Noguchi S et al: $\beta$-sarcoglycan (A 3b) mutations cause autosomal recessive muscular dystrophy with loss of the sarcoglycan complex. $\mathrm{N}$ at $\mathrm{G}$ enet 1995; 11: 266-273.

$7 \mathrm{Lim} \mathrm{LE}, \mathrm{Duclos} F, B$ roux 0 , Bourg $N$ et al: $\beta$-sarcoglycan (43 DA G): Characterization and involvement in a recessive form of limb-girdle muscular dystrophy linked to chromosome 4q12. Nat G enet 1995; 11: 257-265.

8 N oguchi S, M cNally E M, B en Othmane $K$ et al: M utations in the dystrophin-associated protein $\gamma$-sarcoglycan in chromosome 13 muscular dystrophy. Science 1995; 270: 819-822.

9 M CNally E M, Passos-Bueno MR, B onnemann CG, Vainzof $M$, Moreira ES et al: Mild and severe muscular dystrophy caused by a single $\gamma$-sarcoglycan mutation. A m J H um G enet 1996; 59: 1040-1047.

10 Passos-Bueno MR, Moreira ES, Vainzof $M$, M arie SK, Zatz $M$ : Linkage analysis in autosomal recessive limbgirdle muscular dystrophy (AR-LGMD) maps a sixth form to 5q33-34 (LGMD 2F) and indicates that there is at least one more subtype of AR LGMD. Hum Mol G enet 1996; 5: 815-820.

11 Nigro V, Moreira HS, Piluso $G$ et al: The $5 q$ autosomal recessive limb-girdle muscular dystrophy, LGMD2F, is caused by a mutation in the $\delta$-sarcoglycan gene. $\mathrm{N}$ at $\mathrm{G}$ enet 1996; 14: 195- 198.
12 Vainzof M, Passos-Bueno MR, M oreira ES et al: The sarcoglycan complex in the six autosomal recessive limbgirdle (AR-LGMD) muscular dystrophies. $\mathrm{H}$ um $\mathrm{Mol}$ G enet 1996; 5: 1963-1969.

13 Moreira ES, Vainzof $M, M$ arie SK, Nigro V, Z atz $M$, Passos-Bueno MR: A first missense mutation in the $\delta$-sarcoglycan gene associated with a severe phenotype and frequency of limb-girdle muscular dystrophy type $2 \mathrm{~F}$ (L GM D 2F) among Brazilian sarcoglycanopathies. (Submitted). J Med G enet 1998; 35: (in press).

14 Ho-K im M A, B edard A, Vincent M, Rogers PA : D ystrophin: $A$ sensitive and reliable immunochemical assay in tissue and cell culture homogenates. Biochem Biophys Res Comm 1991; 181: 1164-1172.

15 Karpati G, Zubrzycka-G aarn EE, Carpenter S, Bulman $D E$, Ray PN, Worton RG: A ge-related conversion of dystrophin negative to positive fibre segments of skeletal but not cardiac muscle fibres in heterozygote mdx mice. J Neuropathol Exp Neurol 1990; 49: 96-105.

16 Vainzof M, Nicholson LVB, Bulman DE et al: Sarcolemmal distribution of abnormal dystrophin in X p21 carriers. Neuromusc D isord 1993; 3: 135-140.

17 Vainzof M, Passos-Bueno M R, Pavanello R CM, Zatz M : Is dystrophin always altered in Becker muscular dystrophy patients? J N eurol Sci 1995; 131: 99-104. 